\title{
Management of malignant pleural effusions with indwelling pleural catheters or talc pleurodesis
}

\author{
Nadim Srour MD MSc $\mathrm{C}^{1,2}$, Kayvan Amjadi $\mathrm{MD}^{1,3}$, \\ Alan John Forster MD MSc1,2,3,4,5, Shawn David Aaron MD MSc $c^{1,2,3}$
}

$\mathrm{N}$ Srour, K Amjadi, AJ Forster, SD Aaron. Management of malignant pleural effusions with indwelling pleural catheters or talc pleurodesis. Can Respir J 2013;20(2):106-110.

BACKGROUND: Management of malignant pleural effusion typically involves insertion of an indwelling pleural catheter (IPC) or chemical pleurodesis with agents such as talc.

OBJECTIVES: To compare these management strategies with regard to success of pleural effusion management.

METHODS: A retrospective cohort study was designed comparing patients with malignant and paramalignant pleural effusions and Eastern Cooperative Oncology Group performance status $<4$ managed with IPC insertion or talc pleurodesis (TP) through tube thoracostomy during noncontemporary three-year periods at a single centre.

RESULTS: The IPC and TP groups comprised 193 and 167 patients, respectively. The pleural effusion control rate at six months was higher in the IPC group ( $52.7 \%$ versus $34.4 \%$ in the TP group; $\mathrm{P}<0.01$ ), but the rate of freedom from catheter at 90 days and pleural effusion at 180 days was not significantly different (IPC 25.8\% versus TP 34.4\% [P=0.17]). Median effusion-free survival from the date of catheter insertion was significantly longer in the IPC group (101 days versus 58 days in the TP group; log-rank $\mathrm{P}=0.025$ ). Both procedures were safe.

DISCUSSION: While the results suggest better pleural effusion control and longer effusion-free survival with IPC insertion compared with TP, the present study had several limitations. Other recent studies have not shown one strategy to be clearly superior to the other.

CONCLUSION: Both IPC insertion and TP remain acceptable options for the management of malignant pleural effusions.

Key Words: IPC; Lung cancer; Malignant pleural effusion; Palliative care; Pleural disease; Talc pleurodesis

\section{La prise en charge des épanchements pleuraux malins causés par des sondes pleurales à demeure ou par une symphyse par talc}

\begin{abstract}
HISTORIQUE : En général, la prise en charge d'épanchements pleuraux malins exige l'insertion d'une sonde pleurale à demeure (SPD) ou une symphyse chimique au moyen d'agents comme le talc.

OBJECTIFS : Comparer ces stratégies par rapport à leur réussite pour prendre en charge l'épanchement pleural.

MÉTHODOLOGIE : Les chercheurs ont conçu une étude de cohorte rétrospective comparant des patients ayant des épanchements malins et paramalins et l'état de rendement inférieur à 4 du groupe coopératif d'oncologie pris en charge par insertion d'une SPD ou par symphyse par talc (ST) au moyen d'une thoracotomie pendant des périodes non contemporaines de trois ans au sein d'un même centre.
\end{abstract}

RÉSULTATS : Les groupes de SPD et de ST se composaient de 193 et de 167 patients, respectivement. Le taux de contrôle des épanchements pleuraux au bout de six mois était plus élevé au sein du groupe de SPD $(52,7 \%$ par rapport à $34,4 \%$ dans le groupe de $\mathrm{ST} ; \mathrm{P}<0,01$ ), mais le taux de retrait de la sonde au bout de 90 jours et d'épanchement pleural au bout de 180 jours ne différait pas de manière significative (SPD 25,8 \% par rapport à ST 34,4 \% $[\mathrm{P}=0,17])$. La survie médiane sans épanchement à compter de la date d'insertion de la sonde était considérablement plus longue dans le groupe de SPD (101 jours par rapport à 58 jours dans le groupe ST, valeur P de Mantel Haenszel=0,025). Les deux interventions étaient sécuritaires.

EXPOSÉ : D'après les résultats, le contrôle des épanchements pleuraux et la survie sans épanchements étaient plus longs après l'insertion d'une SPD qu'après une ST, mais la présente étude comporte plusieurs limites. D'autres études récentes n'ont pas démontré la supériorité évidente d'une stratégie par rapport à l'autre.

CONCLUSION : Tant l'insertion d'une SPD que la ST sont des solutions acceptables pour prendre en charge les épanchements pleuraux malins.

Putnam et al (11) conducted a randomized controlled trial comparing chemical pleurodesis (with doxycycline) with IPC insertion in 144 patients. While $97 \%$ of IPC patients experienced, at most, a small pleural effusion after the procedure, initial treatment was unsuccessful in $32 \%$ of patients assigned to the chemical pleurodesis group. Despite this, symptom improvement, quality of life and the rate of pleural effusion recurrence after initial successful control were not significantly different between the two groups.

Intrapleural talc is a potentially more efficacious agent than doxycycline (15). In a retrospective study comparing IPC insertion with talc chemical pleurodesis, the length of stay was shorter and fewer reinterventions for recurrent ipsilateral effusions were required in the IPC group, as could be expected. However, the rate of complications was not significantly different between the two groups (16). A recent nonrandomized prospective study compared IPC insertion with talc chemical pleurodesis and found that patients treated using an IPC spent fewer days in hospital and had better quality of life after one week (17). However, pleural effusion control was not significantly different between the groups. A nonblinded, randomized controlled trial cases - a phenomenon termed spontaneous pleurodesis $(2,3,7,8,10-14)$

\footnotetext{
${ }^{1}$ Department of Medicine, The Ottawa Hospital; ${ }^{2}$ The Ottawa Hospital Research Institute; ${ }^{3}$ Faculty of Medicine, The University of Ottawa;

${ }^{4}$ Institute For Clinical Evaluative Sciences; ${ }^{5}$ The Telfer School of Management, University of Ottawa, Ottawa, Ontario

Correspondence: Dr Nadim Srour, The Ottawa Hospital Civic campus - Box 211, 1053 Carling Avenue, Ottawa, Ontario K1Y 4E9.

Telephone 613-798-5555 ext 16523,fax613-761-5333,e-mail nsrour@ohri.ca
} 
comparing IPC insertion and talc pleurodesis was recently conducted (18). There was no significant difference in dyspnea between the groups during the first 42 days, at six weeks or at three months; however, patients in the IPC group were significantly less dyspneic at six months. There was also no significant difference in quality of life. However, there was a substantially higher rate of serious pleural infections $(9.6 \%)$ in the IPC group. Despite these trials, the evidence does not support recommending a strategy of IPC insertion or pleurodesis over the other.

The objective of the present study was to compare well-defined pleural effusion management success outcomes in patients with malignant or paramalignant pleural effusions who were treated with IPC insertion compared with those treated with talc chemical pleurodesis.

\section{METHODS}

\section{Study design and setting}

A retrospective cohort study comparing noncontemporary groups of patients who underwent either talc pleurodesis through tube thoracostomy (mostly pigtail tubes) or IPC insertion (PleurX, CareFusion, USA) for management of a malignant or paramalignant pleural effusion at The Ottawa Hospital (Ottawa, Ontario) was conducted. Talc pleurodesis has been only very rarely performed since the IPC Program began in 2006. The investigational protocol was reviewed and approved by The Ottawa Hospital Research Ethics Board.

\section{Participants}

IPC cases were identified from The Ottawa Hospital IPC Program database, a prospectively maintained database referencing all patients who have undergone IPC insertion since the program began in 2006. Cases of talc pleurodesis were identified through the prescription of talc, as determined from the Ottawa Hospital Data Warehouse, a relational database replicating information from several institutional information systems. Patient care was the primary purpose for the source system of the data that were extracted. The inclusion criteria were the following: tube thoracostomy followed by talc pleurodesis between March 1, 2003 and February 28, 2006, or insertion of an IPC between May 1, 2006 and April 31, 2009; procedure performed for management of a pleural effusion as opposed to a pneumothorax; biopsy-proven diagnosis of malignancy or malignancy strongly suspected by the treating physician; presence of malignant cells on pleural fluid or, in the absence of positive pleural fluid cytology, the pleural effusion was believed to be secondary to malignancy. The following patients were excluded: Eastern Cooperative Oncology Group (ECOG) performance status of 4 (completely disabled and confined to bed or chair); previous ipsilateral pleurodesis or IPC; previous or simultaneous contralateral pleurodesis or IPC (in the case of simultaneous bilateral procedures, one of the two procedures was excluded as determined by a computer algorithm using a pseudorandom number generator); if the tube thoracostomy, pleurodesis or IPC insertion was performed in the setting of another procedure such as medical pleuroscopy or video-assisted thoracic surgery. Patients with an ECOG status of 4 were excluded because it was considered possible that subjects with a poor performance status may have undergone IPC insertion from 2006 to 2009 while these subjects may not have been offered chemical pleurodesis from 2003 to 2006. Therefore, all subjects with an ECOG status of 4 were excluded to make the two groups more comparable and to avoid introducing potential selection bias into the analysis. Those who had their intervention performed in the setting of another procedure, such as video-assisted thoracic surgery, were excluded because they may not be representative of the same population.

\section{Procedures}

Talc pleurodesis was performed by the treating team using $5 \mathrm{~g}$ of talc (except for one patient who received $2.5 \mathrm{~g}$ ) from a North American source (Medisca Pharma, Canada). IPC insertion was performed by one of the investigators (KA) on both inpatients and outpatients. Home care visited the patients in the IPC group three times weekly for drainage. Catheters were removed when drainage volumes were $<50 \mathrm{~mL}$ on three consecutive visits, unless the patient reported increased dyspnea and there was radiological evidence of pleural fluid reaccumulation on imaging suggestive of catheter blockage or loculation.

\section{Outcomes}

The primary end point was pleural effusion control. Pleural effusion control was defined as no evidence of a moderate or large pleural effusion within 180 days of catheter insertion. Subjects whose status could not be determined due to death or loss to radiological follow-up were excluded. It was not possible to blindly determine the presence and size of pleural effusions because the chest $\mathrm{x}$-rays in the IPC period were digital images and a significant proportion of the chest $\mathrm{x}$-rays from the talc pleurodesis period were not. To avoid ascertainment bias, the presence of a moderate or large pleural effusion was, therefore, determined from radiology reports.

Secondary outcomes included freedom from pleural effusion and catheter, need for subsequent intervention, survival, effusion-free survival and adverse events. Quality of life measures were not available and symptom control could not be reliably assessed.

Freedom from pleural effusion and catheter was defined as removal of the catheter, for any reason, within 90 days after catheter insertion with the absence of evidence of persistence or recurrence of a moderate pleural effusion within 180 days of catheter insertion. This definition was devised such that there would be time for a pleural effusion to recur after catheter removal. Subjects whose status could not be determined due to death or loss to radiological follow-up were excluded.

Survival was computed from the time of catheter insertion until death. Date of death was determined from the Ottawa Hospital Data Warehouse, medical records or the provincial vital statistics office. Survival until death was also alternatively computed from the first time the pleural effusion was mentioned on a thoracic imaging report at the Ottawa Hospital. This alternative analysis of survival was performed as a sensitivity analysis to exclude lead time bias potentially arising from differing delays to intervention. Effusion-free survival was defined as survival without recurrence of a pleural effusion at least moderate in size, calculated from the time of catheter insertion.

ECOG performance status before intervention was obtained from the IPC Program database for the IPC group and was determined from medical records for the chemical pleurodesis group. ECOG status was categorized as $4,<4$ or unknown. Information obtained from the Ottawa Hospital Data Warehouse was used to determined whether the catheter insertion procedure was performed in an inpatient setting for the IPC group. All talc pleurodesis procedures were performed in the inpatient setting. Adverse events were recorded from the IPC Program database for the IPC group and medical records for the talc pleurodesis group.

\section{Study size}

The sample size was determined by the number of available cases. The study period for the IPC group began three months after the inception of the IPC Program at the Ottawa Hospital in 2006 and lasted three years, to allow for one year of follow-up at the time of data collection. A study period of similar duration was chosen for the talc pleurodesis group.

\section{Statistical methods}

SAS version 9.2 (SAS Institute Inc, USA) was used for statistical analysis. A statistical significance level of 0.05 was chosen for all analyses. Proportions were compared between groups using the $\chi^{2}$ test of independence. The need for subsequent procedures and adverse events were compared using Fisher's exact test. Continuous variables were compared using Student's $t$ test for independent samples.

Logistic regression was used to adjust for potential important clinical confounders determined a priori including sex, age, pleural fluid $\mathrm{pH}$ and lactate dehydrogenase levels, presence of malignant cells on pleural fluid cytology, tumour type, history of thoracic irradiation and side of catheter insertion. These covariates were selected because they 


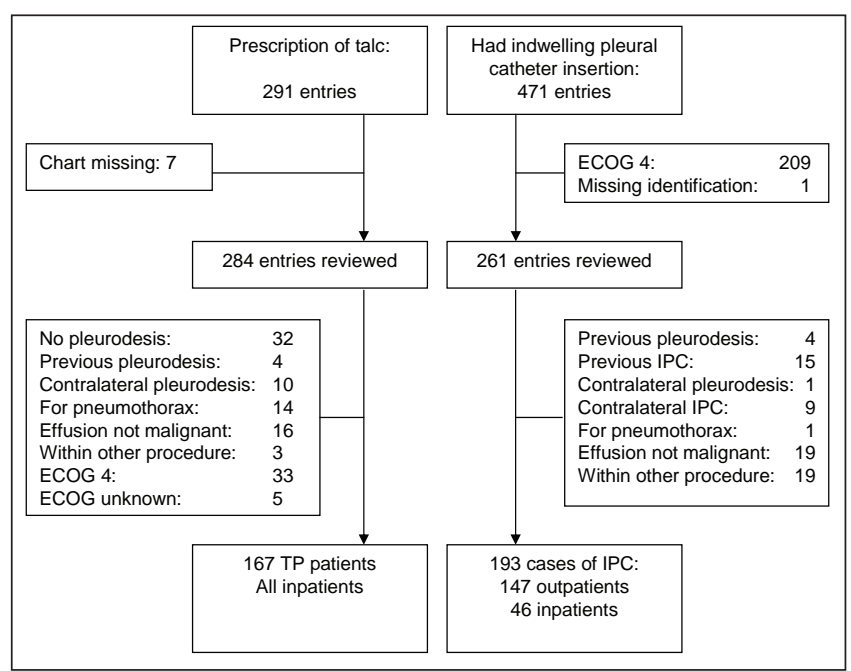

Figure 1) Case selection. ECOG Eastern Cooperative Oncology Group; IPC Indwelling pleural catheter; TP Talc pleurodesis

TABLE 1

Characteristics according to group

\begin{tabular}{lccc}
\hline & \multicolumn{2}{c}{ Group } & \\
\cline { 2 - 3 } Characteristic & TP (n=167) & IPC (n=193) & P \\
\hline Age, years, mean (95\% CI) & $65.1(63.2-67.0)$ & $67.1(65.3-68.9)$ & 0.14 \\
Sex & & & 0.004 \\
$\quad$ Male & $49(29.3)$ & $85(44.0)$ & \\
$\quad$ Female & $118(70.7)$ & $108(56.0)$ & \\
History of previous chest & $66(39.5)$ & $63(32.6)$ & 0.19 \\
$\quad$ irradiation & & & \\
Primary tumour type & & & \\
$\quad$ Lung & $73(43.7)$ & $81(42.0)$ & 0.52 \\
$\quad$ Breast & $44(26.3)$ & $43(22.3)$ & 0.91 \\
$\quad$ Gynecological & $24(14.4)$ & $10(5.2)$ & 0.02 \\
$\quad$ Lymphoma & $4(2.4)$ & $17(8.8)$ & 0.005 \\
Mesothelioma & $2(1.2)$ & $12(6.2)$ & 0.008 \\
$\quad$ Other & $20(26.3)$ & $30(15.5)$ & 0.16 \\
Intervention side & & & 0.81 \\
$\quad$ Right & $94(56.3)$ & $111(57.5)$ & \\
$\quad$ Left & $73(43.7)$ & $82(42.5)$ & \\
Pleural fluid cytology samples/ & 1.28 & 1.54 & 0.009 \\
$\quad$ subject, mean (95\% Cl) & $(1.14-1.42)$ & $(1.41-1.67)$ & \\
Malignant pleural fluid cytology & $65(38.9)$ & $93(48.2)$ & 0.08 \\
\hline
\end{tabular}

Data presented as $n$ (\%) unless otherwise indicated. IPC Indwelling pleural catheter; TP Talc pleurodesis

were known or possible predictors of either mortality or spontaneous pleurodesis, and all adjusted models included all of the covariates. When correcting for age in adjusted analyses, age (in years) was grouped in the following categories: 49 or younger, 50 to 64,65 to 79 and 80 or older. Underlying tumour types were classified as lung cancer, breast cancer, lymphoma, mesothelioma, gynecological malignancies and other.

All survival analyses were conducted using the Kaplan-Meier method and groups were compared using the log-rank test. Cox proportional hazards regression was performed to adjust for the confounders listed above.

Unadjusted comparisons of rates of control of pleural effusions and rates of freedom from pleural effusion and catheter between the two groups were performed using the $\chi^{2}$ test of independence. Logistic regression was used to adjust for the potential confounders listed above. The Wald $\chi^{2}$ statistic was used to determine significance at the 0.05 level.
TABLE 2

Comparison of strategy success

\begin{tabular}{lccccc}
\hline & \multicolumn{2}{c}{ Group, \% } & & \multicolumn{2}{c}{ OR (95\% Cl), P } \\
\cline { 2 - 3 } \cline { 5 - 6 } Clinical outcome & TP & IPC & & Unadjusted & Adjusted \\
\hline Pleural effusion control & 34.4 & 52.7 & & $2.12(1.20-3.74)$, & $2.46(1.31-4.65)$, \\
& & & & 0.009 & $0.005^{*}$ \\
Freedom from catheter & 34.4 & 25.8 & & $0.66(0.37-1.20)$, & $0.70(0.36-1.34)$, \\
and pleural effusion & & & & 0.17 & $0.28^{*}$ \\
\hline *Based on Wald X $^{2}$ IPC Indwelling pleural catheter. TP Talc pleurodesis
\end{tabular}

\section{RESULTS}

Many more subjects were considered for inclusion in the IPC group than the talc pleurodesis group during time periods of the same duration (Figure 1). This difference was mainly due to the expected higher number of subjects with an ECOG performance status of 4 who underwent IPC compared with talc pleurodesis. In the IPC group, the ECOG performance status was 1 in 13 patients (6.7\%), 2 in 48 patients (24.9\%) and 3 in 132 patients $(68.4 \%)$. In the talc pleurodesis group, only an ECOG performance status of 4 or $<4$ could be determined accurately. The proportion of females was higher in the talc pleurodesis group (Table 1). There was a higher proportion of patients with gynecological malignancy and a lower proportion of patients with lymphoma or mesothelioma in the talc pleurodesis group. In total, 193 and 167 patients were included in the IPC and talc pleurodesis groups, respectively. There were 167 deaths in the IPC group and 156 deaths in the talc pleurodesis group over the three-year study period.

The pleural effusion control rate (Table 2) was higher in the IPC group, both before (OR 2.1 [95\% CI 1.2 to 3.7]) and after adjustment for confounders (OR 2.5 [95\% CI 1.3 to 4.6]). However, the rates of freedom from pleural effusion and catheter were not significantly different (unadjusted OR 0.66 [95\% CI 0.37 to 1.2]; adjusted OR 0.70 [95\% CI 0.36 to 1.34$]$ ).

Survival from the time of catheter insertion was significantly longer in the IPC group (Figure 2), with a median survival of 148 days compared with 133 days in the talc pleurodesis group (log-rank $\mathrm{P}=0.044$ ). Adjustment for potential confounders using Cox regression did not change this conclusion (HR 0.74; $\mathrm{P}=0.011$ ). The same conclusions held when computing survival from the time the pleural effusion was first noted on thoracic radiology reports (unadjusted analysis: log-rank $\mathrm{P}=0.030$; adjusted analysis: $\mathrm{HR} 0.74 ; \mathrm{P}=0.010$ ).

Effusion-free survival was significantly longer in the IPC group at 101 days compared with 58 days in the talc pleurodesis group $(P=0.025$, Figure 3$)$. Effusion-free survival was also significantly longer in the IPC group after adjustment for confounders (HR 0.76; $\mathrm{P}=0.021$ ).

Only one patient in the talc pleurodesis group and two in the IPC group required video-assisted thorascopic surgery or pleuroscopy $(\mathrm{P}=1.0)$. However, a higher proportion of patients in the talc pleurodesis group required further thoracostomy $(15.6 \%$ versus $7.3 \%$; $\mathrm{P}=0.01$ ).

In the IPC group, the catheter was removed before death in 96 of 193 patients $(49.7 \%)$. There was recurrence of a pleural effusion in 26 patients after they had their IPC removed and nine patients had their catheter removed despite having had recurrence of a moderate pleural effusion. In total, 61 of 193 patients (31.6\%) had their catheter removed without recurrence at any time.

The development of symptomatic loculations was the most common adverse event in both groups followed by the development of a moderate or large pneumothorax (Table 3). Only one case of acute respiratory distress syndrome $(0.6 \%)$ occurred following talc pleurodesis. Transient respiratory deterioration, defined as increased dyspnea or oxygen requirement lasting $\leq 48 \mathrm{~h}$, occurred in $3.6 \%$ of patients treated with talc pleurodesis but did not occur in any patients treated with an IPC $(\mathrm{P}=0.004)$. 


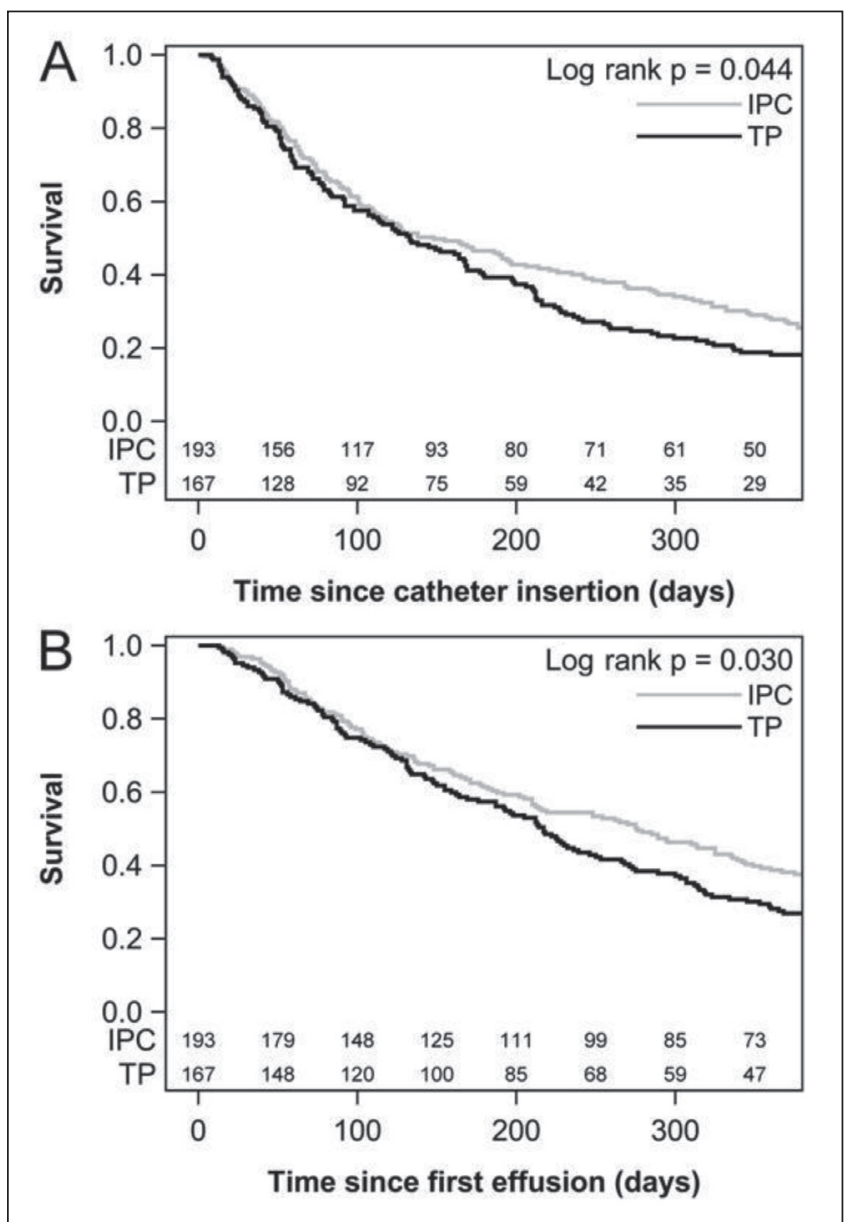

Figure 2) Kaplan-Meier survival analysis. A Survival calculated from time of catheter insertion. B Survival calculated from the first report of a pleural effusion. IPC Indwelling pleural catheter; TP Talc pleurodesis

\section{DISCUSSION}

The pleural effusion control rate was higher in the IPC group $(52.7 \%)$ compared with the talc pleurodesis group $(34.4 \%)$. While the success of talc slurry pleurodesis has been reported to be as high as 71\% (19), this is usually assessed 30 days after the procedure, while our definition of pleural effusion control was much more stringent, requiring the absence of recurrence of a moderate pleural effusion for at least 180 days. In fact, Dresler et al (19) reported late recurrence of a pleural effusion in $28 \%$ of patients who underwent a follow-up assessement more than 30 days after the intervention in a study comparing talc slurry and talc poudrage. Furthermore, it is likely that many subjects considered to have poor control actually had a trapped lung that could not reexpand regardless of which treatment modality was used. This would further contribute to lower the pleural effusion control rates. Unfortunately, we could not determine the presence of trapped lung physiology from the available data. We note that thoracoscopic talc insufflation in patients with lung and breast cancer is associated with a higher rate of survival without recurrence (19) than the talc slurry used in the present study and may compare more favourably with IPC insertion with regard to pleural effusion control.

Subjects in the IPC group had to contend with having the indwelling catheter attached to their body, leading to the inability to take baths and other burdens such as care of the catheter and home care visits. Therefore, we compared strategies by devising an outcome that required removal of the catheter within 90 days with absence of recurrence of effusion within 180 days (ie, freedom from pleural effusion and catheter). With this alternative analysis, there no longer was a difference in success between groups. However, this measure of success

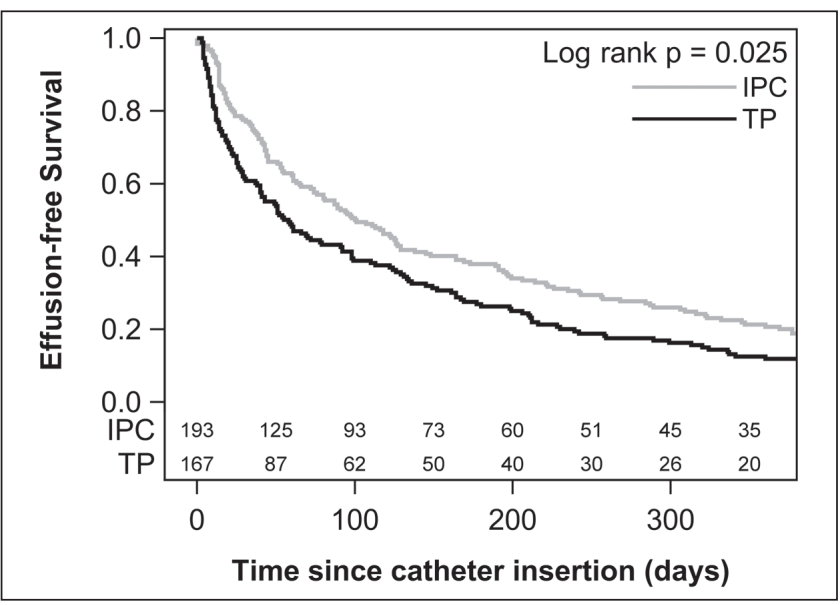

Figure 3) Kaplan-Meier analysis of effusion-free survival. IPC Indwelling pleural catheter; TP Talc pleurodesis

TABLE 3

Adverse events

\begin{tabular}{lccc}
\hline \multirow{2}{*}{ Complication } & \multicolumn{2}{c}{ Group } & \\
\cline { 2 - 3 } Symptomatic loculation & TP & IPC & P \\
Empyema & $20(12.0)$ & $20(10.4)$ & 0.74 \\
Moderate or large pneumothorax & $3(1.8)$ & $4(2.1)$ & 1.00 \\
Subcutaneous emphysema & $8(4.8)$ & $9(4.7)$ & 1.00 \\
Cellulitis & $3(1.8)$ & $0(0.0)$ & 0.10 \\
Blocked catheter & $2(1.2)$ & $5(2.6)$ & 0.46 \\
Dislodged catheter & $4(2.4)$ & $4(2.1)$ & 1.00 \\
Bleeding & $5(3.0)$ & $2(1.0)$ & 0.26 \\
Tumour seeding & $1(0.6)$ & $0(0.0)$ & 0.46 \\
Pain requiring catheter removal & $1(0.6)$ & $0(0.0)$ & 0.46 \\
Transient respiratory deterioration & $7(4.2)$ & $2(1.0)$ & 0.087 \\
ARDS & $6(3.6)$ & $0(0.0)$ & 0.004 \\
Fever & $1(0.6)$ & $0(0.0)$ & 0.46 \\
Fluid leak & $7(4.2)$ & $2(1.0)$ & 0.087 \\
\hline
\end{tabular}

Data presented as $n(\%)$ unless otherwise indicated. ARDS Acute respiratory distress syndrome; IPC Indwelling pleural catheter; TP Talc pleurodesis

was also imperfect because it put the disutility associated with an indwelling catheter at par with the disutility associated with dyspnea due to pleural effusion. It is probable that these disutilities are not of the same order of magnitude. In the palliative setting, measures of quality of life would be more appropriate. Quality of life was, in fact, assessed in a recent randomized controlled trial but was not significantly different between the IPC and talc pleurodesis groups (18).

Our data suggest potentially longer survival in subjects with malignant pleural effusions who were treated with an IPC rather than talc pleurodesis. Better pleural effusion control may explain the longer survival in the IPC group. Indeed, in a study of talc pleurodesis (20), patients with recurrence of symptomatic effusion had a significantly shorter survival (20). A lead-time bias may be present if delays to intervention were different for the two procedures. We attempted to correct for possible lead-time bias by performing an alternative survival time analysis from the first time thoracic imaging at our institution reported a pleural effusion. This alternative sensitivity analysis also revealed a survival advantage for the IPC group. However, the clinical significance of a potential improvement in median survival of 15 days associated with IPC is uncertain, especially given methodological limitations.

Many patients were censored from some of the outcome analyses due to death or loss to follow-up before 180 days. To properly account for this censoring, and given that both death and failure of pleural 
effusion control are undesirable, we performed an analysis of effusionfree survival (time of catheter insertion to death or recurrence of a pleural effusion at least moderate in size). This particular analysis favoured the IPC group, with a median effusion-free survival of 101 days compared with 58 days in the talc pleurodesis group. This difference was larger and perhaps more clinically relevant that the small potential difference in survival itself.

Because talc pleurodesis is believed to carry higher risk, we surmised that some patients would have been deemed too ill to undergo talc pleurodesis and would have been selected out of that group while patients with similar characteristics would have been included in the IPC group. In fact, it appears that more patients with ECOG 4 status were offered IPC insertion from 2006 to 2009 compared with those who had been offered talc pleurodesis from 2003 to 2006 (Figure 1). Therefore, we excluded all subjects with an ECOG status of 4 to make the two groups more comparable and to avoid introducing potential selection bias into the analysis. ECOG performance status may affect outcomes, such as survival, and it would be important to include it as a covariate in the multivariate analyses. Another unfortunate limitation of the present study was that this could not be accomplished because the ECOG performance status could not be determined with sufficient accuracy in the talc pleurodesis group.

There are several other potential limitations to our study, mainly arising from its retrospective cohort design. For instance, the distribution of patient baseline characteristics differed in the two groups: the distribution of underlying tumour types was different, more females were included in the talc pleurodesis group and the patients in the IPC group were more likely to have positive malignant pleural fluid cytology. However, adjusted analyses performed to account for these differences did not change our conclusions. Furthermore, lung and breast cancers accounted for the majority of cases and were well-balanced between the two groups.

The two groups were not contemporary and secular effects may have influenced the results. Conceivably, the survival advantage apparent in the IPC group may be related to better cancer care received in 2006 to 2009 compared with 2003 to 2006, or, potentially, to better care received within the more structured IPC Program.

\section{REFERENCES}

1. Chernow B, Sahn SA. Carcinomatous involvement of the pleura: An analysis of 96 patients. Am J Med 1977;63:695-702.

2. Schneider T, Reimer P, Storz K, et al. Recurrent pleural effusion: Who benefits from a tunneled pleural catheter? Thorac Cardiovasc Surg 2009;57:42-6.

3. Tremblay A, Michaud G. Single-center experience with 250 tunnelled pleural catheter insertions for malignant pleural effusion. Chest 2006;129:362-8

4. Heffner JE, Nietert PJ, Barbieri C. Pleural fluid $\mathrm{pH}$ as a predictor of survival for patients with malignant pleural effusions. Chest 2000;117:79-86.

5. Sanchez-Armengol A, Rodriguez-Panadero F. Survival and talc pleurodesis in metastatic pleural carcinoma, revisited. Report of 125 cases. Chest 1993;104:1482-5.

6. Noppen M. Who's (still) afraid of talc? Eur Respir J 2007;29:619-21.

7. Musani AI, Haas AR, Seijo L, Wilby M, Sterman DH. Outpatient management of malignant pleural effusions with small-bore, tunneled pleural catheters. Respiration 2004;71:559-66.

8. Bertolaccini L, Zamprogna C, Barberis L, et al. Malignant pleural effusions: Review of treatment and our experience. Rev Recent Clin Trials 2007;2:21-5.

9. Warren WH, Kalimi R, Khodadadian LM, Kim AW. Management of malignant pleural effusions using the Pleur(x) catheter. Ann Thorac Surg 2008;85:1049-55.

10. Pollak JS, Burdge CM, Rosenblatt M, Houston JP, Hwu WJ, Murren J. Treatment of malignant pleural effusions with tunneled long-term drainage catheters. J Vasc Interv Radiol 2001;12:201-8.

11. Putnam JB Jr, Light RW, Rodriguez RM, et al. A randomized comparison of IPC and doxycycline pleurodesis in the management of malignant pleural effusions. Cancer 1999;86:1992-9.
While a lower proportion of patients in the IPC group required repeat thoracostomy, this is not surprising and is not truly an advantage because these patients had a chronic indwelling catheter present. Patients in both groups required very few subsequent procedures. The rate of complications was low in both groups, not supporting the concern of some authors for acute respiratory distress syndrome. The rate of empyema was low in the IPC group, similar to most series and in contrast to a recent randomized controlled trial (18).

\section{SUMMARY}

Our results suggest improved pleural effusion control with IPC insertion and longer effusion-free survival. However, there was no significant difference in the rate of freedom from pleural effusion and catheter. Talc pleurodesis appeared to be safer than reported by other authors, although a small but significant proportion of patients suffered transient respiratory deterioration. There are several limitations to our study and our results should be considered hypothesis-generating. Considering other studies on the subject, both IPC insertion and talc pleurodesis remain acceptable options for the management of malignant pleural effusions, at least for patients with an ECOG performance status $<4$.

ACKNOWLEDGEMENTS: Dr Srour contributed to the conception and design of the study and acquisition, analysis and interpretation of data. He drafted the submitted manuscript and provided final approval of the version to be published. Dr Srour had full access to all of the data in the study and takes responsibility for the integrity of the data and the accuracy of the data analysis, including any adverse events. Dr Amjadi participated in data acquisition and revised the submitted manuscript for important intellectual content. He provided final approval of the version to be published. Dr Forster contributed to the conception and design of the study, participated in data acquisition, revised the submitted manuscript for important intellectual content and provided final approval of the version to be published. Dr Aaron contributed to the conception and design of the study and interpretation of data. He has drafted the submitted article and provided final approval of the version to be published. We thank the Office of the Registrar General of the Province of Ontario, Canada for providing vital statistics used in this study.
12. Putnam JB Jr, Walsh GL, Swisher SG, et al. Outpatient management of malignant pleural effusion by a chronic IPC. Ann Thorac Surg 2000;69:369-75.

13. Tremblay A, Mason C, Michaud G. Use of tunnelled catheters for malignant pleural effusions in patients fit for pleurodesis. Eur Respir J 2007;30:759-62.

14. Sioris T, Sihvo E, Salo J, Rasanen J, Knuuttila A. Long-term IPC (PleurX) for malignant pleural effusion unsuitable for talc pleurodesis. Eur J Surg Oncol 2009;35:546-51.

15. Tan C, Sedrakyan A, Browne J, Swift S, Treasure T. The evidence on the effectiveness of management for malignant pleural effusion: A systematic review. Eur J Cardiothorac Surg 2006;29:829-38.

16. Hunt BM, Farivar AS, Vallieres E, et al. Thoracoscopic talc versus tunneled pleural catheters for palliation of malignant pleural effusions. Ann Thorac Surg 2012;94:1053-9.

17. Fysh ET, Waterer GW, Kendall PA, et al. IPCs reduce inpatient days over pleurodesis for malignant pleural effusion. Chest 2012;142:394-400.

18. Davies HE, Mishra EK, Kahan BC, et al. Effect of an IPC vs chest tube and talc pleurodesis for relieving dyspnea in patients with malignant pleural effusion: The TIME2 randomized controlled trial. JAMA 2012;307:2383-9.

19. Dresler CM, Olak J, Herndon JE II, et al. Phase III intergroup study of talc poudrage vs talc slurry sclerosis for malignant pleural effusion. Chest 2005;127:909-15.

20. Love D, White D, Kiroff G. Thoracoscopic talc pleurodesis for malignant pleural effusion. ANZ J Surg 2003;73:19-22. 


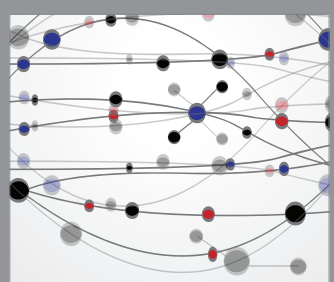

The Scientific World Journal
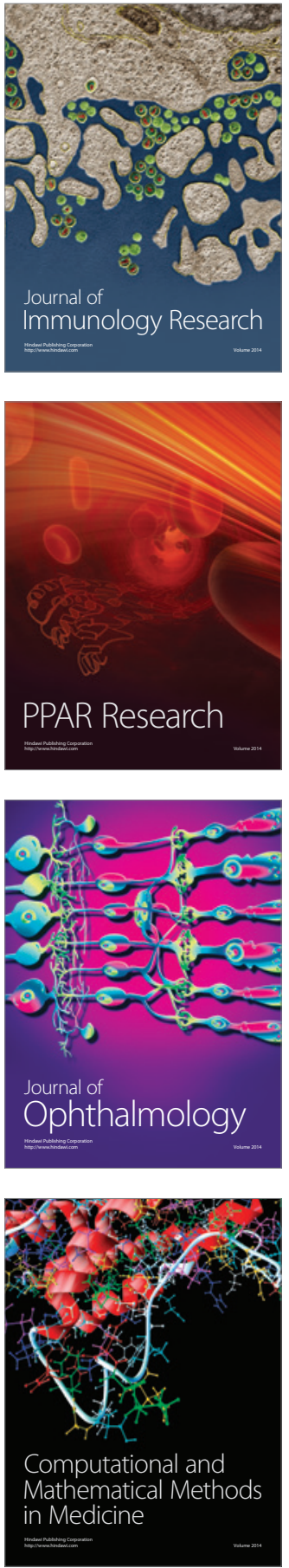

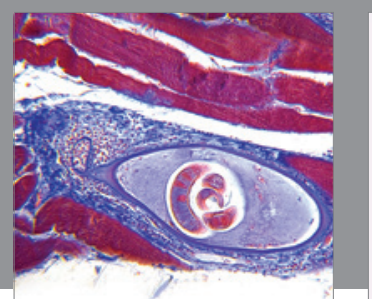

Gastroenterology Research and Practice

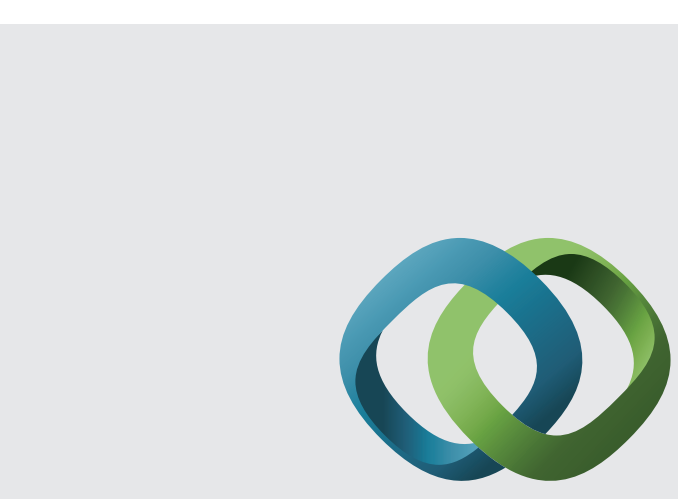

\section{Hindawi}

Submit your manuscripts at

http://www.hindawi.com
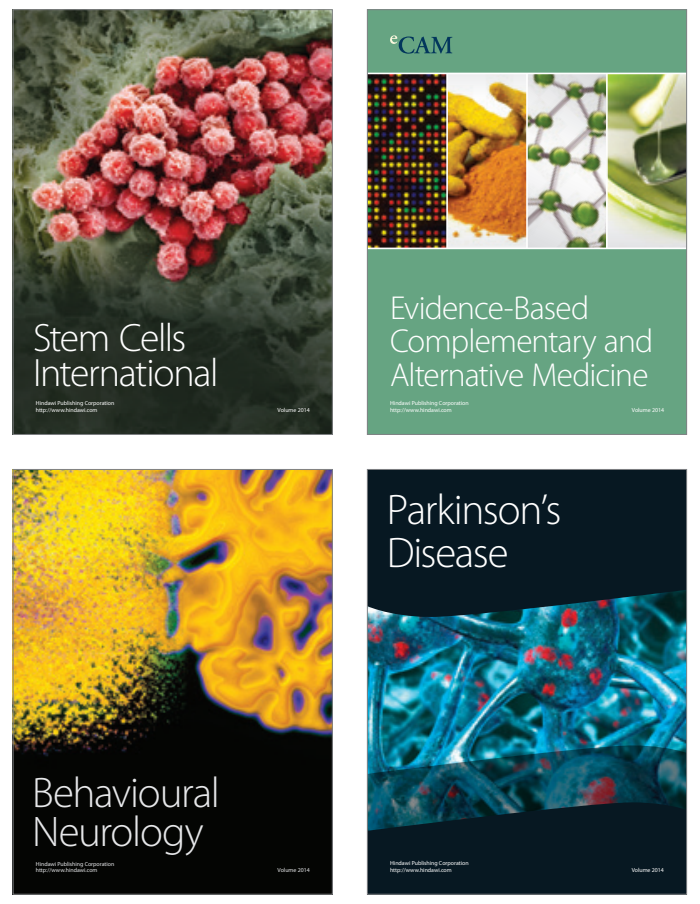
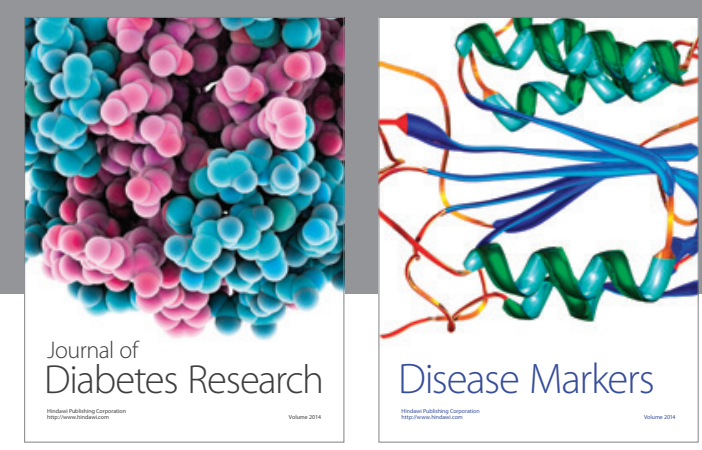

Disease Markers
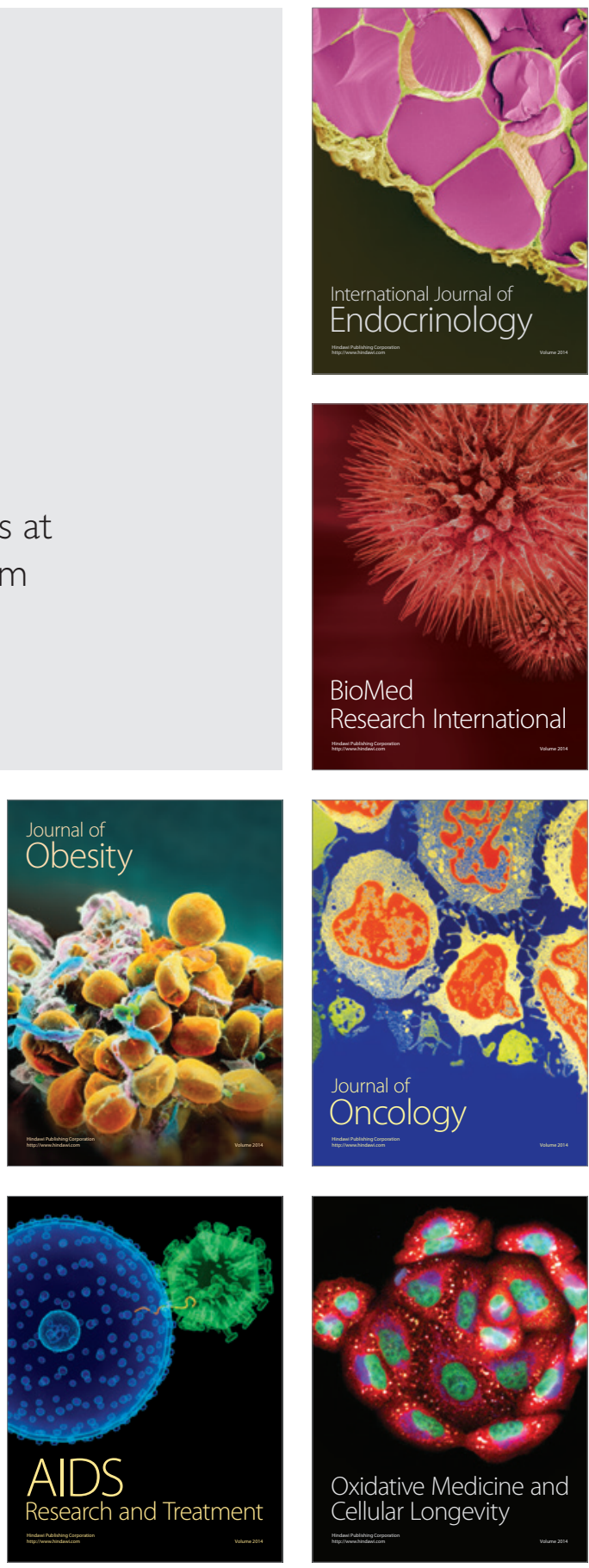